\title{
Involvement of endoplasmic reticulum stress in angiotensin II-induced NLRP3 inflammasome activation in human renal proximal tubular cells in vitro
}

\author{
Jing WANG, Yi WEN, Lin-li LV, Hong LIU, Ri-ning TANG, Kun-ling MA, Bi-cheng LIU*
}

Institute of Nephrology, Zhongda Hospital, Southeast University School of Medicine, Nanjing 210009, China

\begin{abstract}
Aim: NLRP3 inflammasome plays an important role in renal injury and may be a therapeutic target in the treatment of patients with progressive chronic kidney disease. In this study we investigated whether angiotensin II (Ang II)-induced NLRP3 inflammasome activation was linked to endoplasmic reticulum stress (ERS) in human renal proximal tubular cells in vitro.

Methods: Human kidney proximal epithelial cells (HK-2) were pretreated with telmisartan or 4-PBA, and then treated with Ang II. The expression levels of mRNAs and proteins related to NLRP3 inflammasomes and ERS was examined by real-time PCR, Western blot and immunofluorescence.

Results: Treatment with Ang II (10, 100, and $1000 \mathrm{nmol} / \mathrm{L})$ increased the expression of the inflammasome markers NLRP3 and ASC, as well as caspase-1, IL-1 3 , and IL-18 in dose- and time-dependent manners with peak levels detected at $100 \mathrm{nmol} / \mathrm{L}$ and $12 \mathrm{~h}$. Ang II-induced increases in the expression of NLRP3, ASC, caspase-1, IL-1 3 , and IL-18 were significantly reduced by pretreatment with telmisartan $(1 \mu \mathrm{mol} / \mathrm{L})$. Immunofluorescence studies showed that Ang II increased the expression of NLRP3 and ASC, which was inhibited by telmisartan. Furthermore, Ang II treatment increased the expression of ERS markers GRP78 and p-elF2 $\alpha$ in dose- and time-dependent manners, which was significantly reduced by telmisartan. Moreover, Ang II-induced increases in the expression of NLRP3, ASC, caspase-1, IL-1ß, and IL-18 were significantly inhibited by pretreatment with the ERS inhibitor 4-PBA (5 mmol/L).

Conclusion: Ang II treatment induces NLRP3 inflammasome activation in HK-2 cells in vitro and ER stress is involved in this process, which may represent a new mechanism for the renal rennin-angiotensin system to induce tubulointerstitial inflammation.
\end{abstract}

Keywords: human kidney proximal epithelial cells; angiotensin II; telmisartan; 4-PBA; NLRP3; inflammasome; endoplasmic reticulum stress; chronic kidney disease

Acta Pharmacologica Sinica (2015) 36: 821-830; doi: 10.1038/aps.2015.21; published online 25 May 2015

\section{Introduction}

Tubulointerstitial fibrosis is considered to be the final pathway for progressive kidney diseases due to a wide range of pathophysiological processes ${ }^{[1]}$. Numerous studies have shown that the inflammatory response continues throughout the entire process of renal fibrosis and is an important driver of fibro$\operatorname{sis}^{[2]}$.

Ang II is the most powerful biologically active product of the (renin-angiotensin system, RAS) system and mediates its effects via the Ang II type 1 receptor (AT1R) and type 2 receptor $(\mathrm{AT} 2 \mathrm{R})^{[3]}$. Previous studies have shown that Ang II plays an important homeostatic role in (blood pressure, $\mathrm{BP}$ ) regula-

\footnotetext{
* To whom correspondence should be addressed.

E-mail liubc64@163.com

Received 2014-11-05 Accepted 2015-03-06
}

tion, water and salt balance, and tissue growth control under physiological conditions ${ }^{[4]}$. However, accumulating evidence indicates that Ang II is locally formed in the kidney and is an important factor in renal inflammation ${ }^{[5]}$. Recently, Alique et al demonstrated that in Ang II-infused mice, Ang II could induce the renal infiltration of monocytes/macrophages and T lymphocytes $^{[6]}$. In addition, numerous studies have shown that Ang II treatment could increase the expression of pro-inflammatory cytokines (IL-1 $\beta$, IL-6, IL-8, and TNF- $\alpha)^{[7]}$, suggesting that Ang II may promote inflammation through activation of innate or adaptive immune responses.

Inflammasomes, which mediate caspase- 1 dependent maturation of the proinflammatory cytokines interleukin-1 $\beta$ (IL-1 $\beta$ ) and interleukin-18 (IL-18), participate in the innate immune system $^{[8]}$. The NLRP3 inflammasome is the most fully characterized inflammasome ${ }^{[9]}$. Recently, Vilaysane et al showed that 
NLRP3 plays a significant role in renal injury and could be identified as a therapeutic target in the treatment of patients with progressive (chronic kidney disease, CKD) ${ }^{[10]}$. NLRP3 is activated upon exposure to whole pathogens, as well as (pathogen-associated molecular patterns, PAMPs), (dangerassociated molecular patterns, DAMPs), and environmental irritants $^{[11]}$. Our previous studies have shown that albuminuria could stimulate NLRP3 inflammasome expression in BSA-overload nephropathy in rats, which could be inhibited through the use of enalapril ${ }^{[12]}$. Therefore, the objective of this study is to further investigate whether angiotensin II can directly induce inflammasome activation in renal proximal tubular cells and the underlying mechanisms.

\section{Materials and methods Cell culture}

Human kidney proximal epithelial cells (HK-2) were purchased from the China Center for Type Culture Collection (CCTCC). Cells were cultured in DMEM-F12 supplemented with 10\% fetal bovine serum (GIBCO, Carlsbad, CA, USA). The cells were grown at $37^{\circ} \mathrm{C}$ with $5 \% \mathrm{CO}_{2}$. At $70 \%-80 \%$ confluence, the cells were synchronized with a serum-free culture medium for $24 \mathrm{~h}$. Then, Ang II was added in various doses for various periods of time as indicated. HK-2 cells were treated with telmisartan and 4-PBA for $1 \mathrm{~h}$ before the Ang II treatment. The cells were then collected for further study. Ang II, telmisartan (dissolved in dimethyl sulfoxide, Sigma) and 4-PBA were obtained from Sigma (St Louis, MO, USA). The final concentration of DMSO in our experiments did not exceed $0.1 \%$.

\section{Real-time polymerase chain reaction (RT-PCR)}

Total RNA was extracted from the HK-2 cells, and reverse transcription was performed using RNAiso Plus (Takara, Tokyo, Japan). RT-PCR was performed on an ABI 7300 Sequence Detection System (Applied Biosystems, Foster City, CA, USA) using SYBR Green dye according to the manufacturer's protocol. All of the primers are listed in Table 1. $\beta$-Actin served as an internal reference gene. The relative amount of

Table 1. Human TaqMan primers for real-time PCR.

\begin{tabular}{|c|c|c|}
\hline Genes & & Human TaqMan primers \\
\hline \multirow[t]{2}{*}{ NLRP3 } & sense & 5'-AGATGATGTTGGACTGGGCG-3' \\
\hline & antisense & 5'-TCACCTCCCGACAGTGGATA-3' \\
\hline \multirow[t]{2}{*}{ Caspase-1 } & sense & 5'-GCCTGTTCCTGTGATGTGGA-3' \\
\hline & antisense & 5'-САСТTССТGСCСАСАGАCAT-3' \\
\hline \multirow[t]{2}{*}{ IL-1 $1 \beta$} & sense & 5'-AACCTCTTCGAGGCACAAGG-3' \\
\hline & antisense & 5'-GGCGAGCTCAGGTACTTCTG-3' \\
\hline \multirow[t]{2}{*}{ IL-18 } & sense & 5'-GCTTGAATCTAAATTATCAGTC-3' \\
\hline & antisense & 5'-GAAGATTCAAATTGCATCTTAT-3' \\
\hline \multirow[t]{2}{*}{ GRP78 } & sense & 5'-CATCACGCCGTCCTATGTCG-3' \\
\hline & antisense & 5'-CGTCAAAGACCGTGTTCTCG-3' \\
\hline \multirow[t]{2}{*}{$\beta$-actin } & sense & 5'-СTCCATCCTGGCCTCGCTGT-3' \\
\hline & antisense & 5'-GCTGTCACCTTCACCGTTCC-3' \\
\hline
\end{tabular}

mRNA was calculated using the comparative threshold cycle $(\mathrm{Ct})$ method $(\Delta \Delta \mathrm{Ct}$ method).

\section{Western blotting}

Identical amounts of total protein were extracted from the HK-2 cells and separated by sodium dodecyl sulfate polyacrylamide gel electrophoresis. A gel transfer was performed, and the membranes were then blocked with blocking buffer for $1 \mathrm{~h}$ at room temperature. The membranes were subjected to Western blotting using anti-human polyclonal antibodies against caspase-1-p10, interleukin-1 $\beta$ (IL-1 $\beta$ ), interleukin-18 (IL-18), NLRP3, ASC, GRP78, and p-eIF2a (Santa Cruz Biotechnology, Santa Cruz, CA, USA) with horseradish peroxidase-labeled secondary antibodies for $1 \mathrm{~h}$ at $4^{\circ} \mathrm{C}$. Finally, the signals were detected using an ECL Advance system (Amersham Biosciences, Piscataway, NJ, USA). The relative protein expression levels were determined by normalization to $\beta$-actin.

\section{Immunofluorescence}

HK-2 cells were cultured in confocal dishes. Then, the cultures were washed twice with cold PBS and fixed with iced paraformaldehyde for $30 \mathrm{~min}$. Following three extensive washes with PBS, the cells were permeabilized with $0.5 \%$ Triton X-100 for $10 \mathrm{~min}$. After the next three washings, the cells were blocked with $5 \% \mathrm{BSA}$ at $37^{\circ} \mathrm{C}$ for an additional hour. Then, the cells were incubated with anti-NLRP3 and anti-ASC antibodies overnight at $4{ }^{\circ} \mathrm{C}$, followed by incubation with fluorescent secondary antibodies at $37^{\circ} \mathrm{C}$ for $1 \mathrm{~h}$. Finally, the cells were viewed with a confocal microscope.

\section{Statistical analysis}

All data are expressed as the mean $\pm S D$. Student's $t$-test was used to analyze the statistical significance between two groups, and one-way analysis of variance (ANOVA) was used to analyze differences between more than two groups. The results were expressed as a percentage of the control, and the statistical analysis was performed with SPSS (Statistical Package for the Social Sciences) 20.0. A difference was considered significant if the $P$-value was $<0.05$.

\section{Results}

Angiotensin II induced inflammasome activation in tubular epithelial cells

To evaluate inflammasome activation in tubular epithelial cells, we determined the expression levels of caspase-1, IL-1 $\beta$, and IL-18, which were used as markers of inflammasome activation. Based on the RT-PCR and Western blot analyses of cell lysates, the mRNA and protein levels of caspase-1, IL-1 $\beta$, and IL-18 were upregulated by angiotensin II treatment in a dose- $(0,10,100$, and $1000 \mathrm{nmol} / \mathrm{L})$ and time- $(0,6,12$, and 24 h) dependent manner with peaks at $100 \mathrm{nmol} / \mathrm{L}$ and $12 \mathrm{~h}$ (Figure 1) $(P<0.05)$, suggesting that Ang II could induce inflammasome activation in tubular epithelial cells.

Angiotensin II triggered NLRP3 inflammasome activation Because the NLRP3 inflammasome is one of the best under- 
A

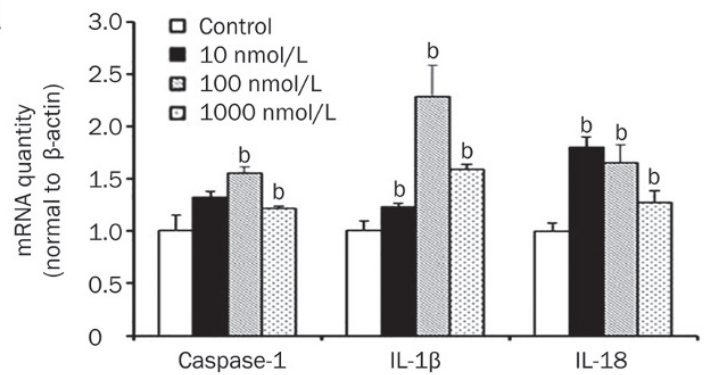

C

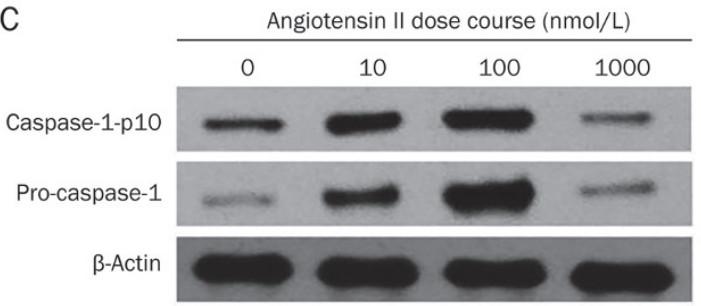

E

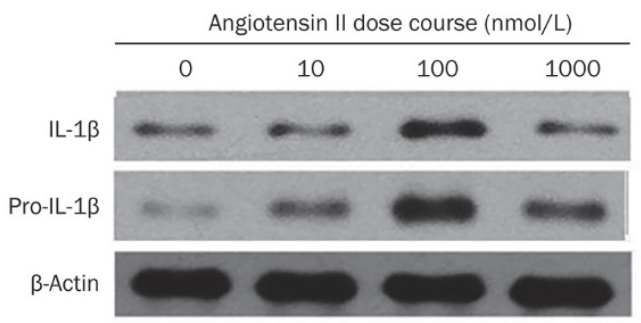

G

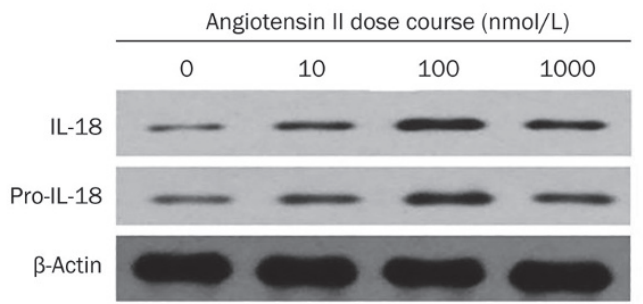

B

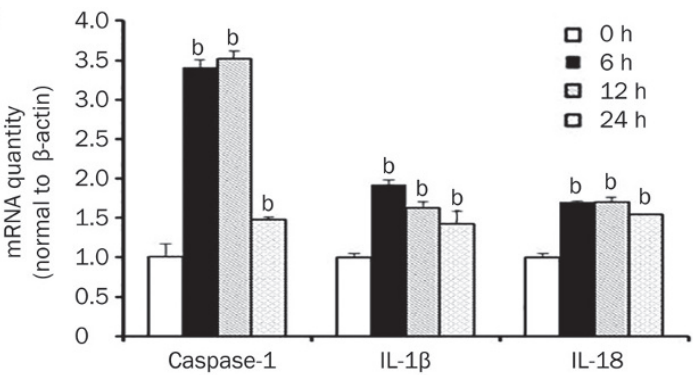

D

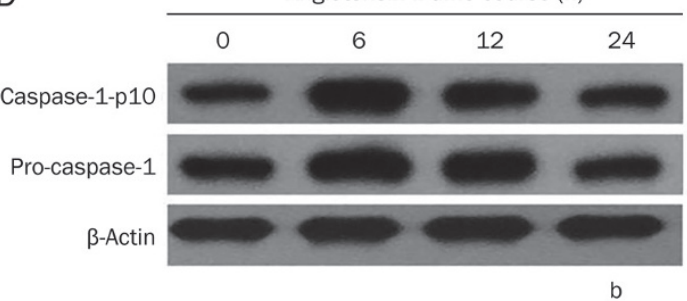

F

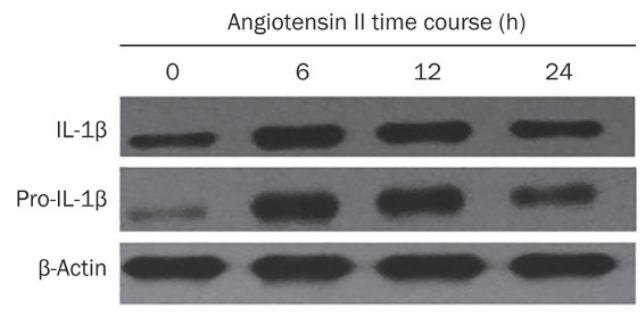

H

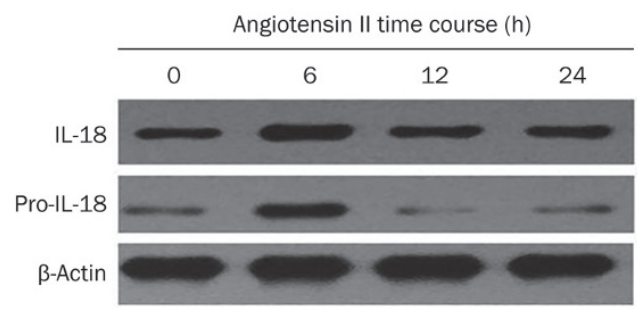

Figure 1. Angiotensin II induced inflammasome activation in tubular epithelial cells. (A) Real-time PCR and (C, E, and G) Western blot analysis show that the mRNA and protein expression of caspase-1, IL-1B, and IL-18 were increased after treatment with different amounts $(0,10,100$, or 1000 $\mathrm{nmol} / \mathrm{L}$ ) of angiotensin II for $12 \mathrm{~h}$ in serum-free medium. (B) Real-time PCR and (D, F, and H) Western blot analysis indicate that the mRNA and protein expression of caspase-1, IL-1 13 , and IL-18 were increased after treatment with $100 \mathrm{nmol} / \mathrm{L}$ angiotensin II for various time periods $(0,6,12$, or $24 \mathrm{~h})$ in serum-free medium. $\beta$-Actin served as an internal control gene. The results represent the mean $\pm \mathrm{SD}$ from four experiments. ${ }^{\mathrm{b}} \mathrm{P}<0.05 \mathrm{vs}$ control.

stood members of the inflammasome family, we next tested the expression of NLRP3 and the adaptor protein apoptosisassociated speck like protein (ASC) after treatment with Ang II. As shown in Figure 2, after the addition of Ang II, NLRP3 and ASC mRNA and protein levels were increased in a dose$(0,10,100$, and $1000 \mathrm{nmol} / \mathrm{L})$ and time- $(0,6,12$, and $24 \mathrm{~h})$ dependent manner $(P<0.05)$. Additionally, the mRNA and protein expression levels of NLRP3 and ASC were markedly increased at $100 \mathrm{nmol} / \mathrm{L}$ and $12 \mathrm{~h}(P<0.05)$. Moreover, immunofluorescence staining showed that NLRP3 and ASC exhibited enhanced expression in the Ang II treatment group, and the proteins were co-localized into the perinuclear space (Figure 3).
Telmisartan inhibited angiotensin II-induced NLRP3 inflammasome activation

To examine whether the NLRP3 inflammasome was activated by Ang II, we applied telmisartan, a known angiotensin II receptor blocker, to HK-2 cells. Then, we pretreated HK-2 cells with or without telmisartan $(1 \mu \mathrm{mol} / \mathrm{L})$. As shown in Figure 4, telmisartan treatment could inhibit Ang II-induced activation of caspase-1 $(P<0.05)$. Likewise, compared to the Ang II treated group, after pretreatment with telmisartan, NLRP3, ASC, IL-1 $\beta$, and IL-18 mRNA and protein levels were reduced $(P<0.05)$. Furthermore, telmisartan could significantly reduce NLRP3 and ASC immunostaining. These data demonstrated that telmisartan could inhibit angiotensin II-induced NLRP3 inflammasome activation. 

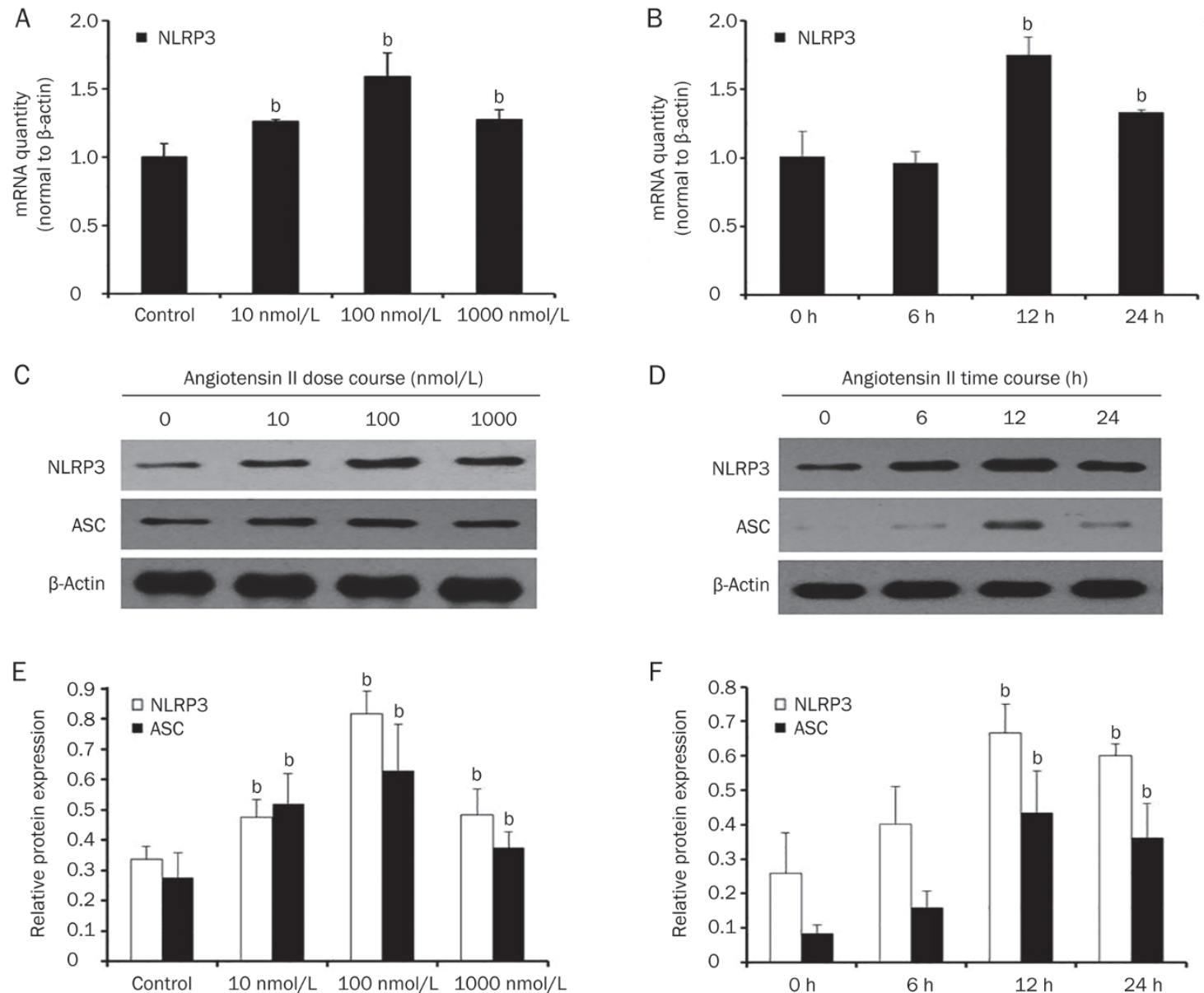

Figure 2. Angiotensin II could trigger NLRP3 inflammasome activation. (A) Real-time PCR and (C and E) Western blot analysis show that the mRNA and protein expression of NLRP3 and ASC were increased after treatment with different amounts $(0,10,100$, and $1000 \mathrm{nmol} / \mathrm{L})$ of angiotensin II for $12 \mathrm{~h}$ in serum-free medium. (B) Real-time PCR and ( $\mathrm{D}$ and F) Western blot analysis indicate that the mRNA and protein expression of NLRP3 and ASC were increased after treatment with $100 \mathrm{nmol} / \mathrm{L}$ angiotensin II for various time periods $(0,6,12$, or $24 \mathrm{~h})$ in serum-free medium. $\beta$-Actin served as an internal control gene. The results represent the mean \pm SD from four experiments. ${ }^{b} P<0.05$ vs control.

Angiotensin II could induce endoplasmic reticulum stress in HK-2 cells

Previous studies demonstrated a close relationship between the NLRP3 inflammasome and endoplasmic reticulum stress. Therefore, we hypothesized that ER stress may be involved in Ang II-induced NLRP3 inflammasome activation. We measured the mRNA and protein expression of GRP78 and the phosphorylation of eIF2a after Ang II treatment. As shown in Figure 5, Ang II remarkably increased the expression of GRP78 and eIF2a phosphorylation in a dose- and time-dependent manner. To further confirm that ER stress was induced by Ang II, we pretreated HK-2 cells with telmisartan. The results showed that telmisartan could reduce the expression of GRP78 at both the mRNA and protein levels as well as eIF2a phosphorylation (Figure 6).

4-Phenyl butyric acid (4-PBA) mediated reduction of ER stress decreased NLRP3 inflammasome activation

To evaluate whether ER stress plays a vital role in regulating
NLRP3 inflammasome activation, we used 4-PBA, a chemical chaperone that reduces ER stress. First, we determined the mRNA and protein expression levels of GRP78 and the phosphorylation of eIF2a to examine the effect of 4-PBA. We found that, compared to the Ang II treated group, 4-PBA could reduce the expression of GRP78 and the phosphorylation of eIF2a (Figure 7B, 7I, and 7J). Next, we treated HK-2 cells with Ang II in the presence or absence of 4-PBA. We found that 4-PBA inhibited Ang II induced the activation of caspase-1 and reduced the expression of NLRP3, ASC, IL-1 $\beta$, and IL-18 (Figure 7A, 7C-7H), which suggests that ER stress plays a significant role in regulating inflammasome activation.

\section{Discussion}

It is now clear that Ang II is an important cytokine for kidney inflammation $^{[13]}$. Numerous studies in experimental models in rodents have shown that Ang II induces the recruitment of monocytes and promotes tubular inflammatory changes in the kidney ${ }^{[14]}$. Most recently, Rafiq et al demonstrated that in 

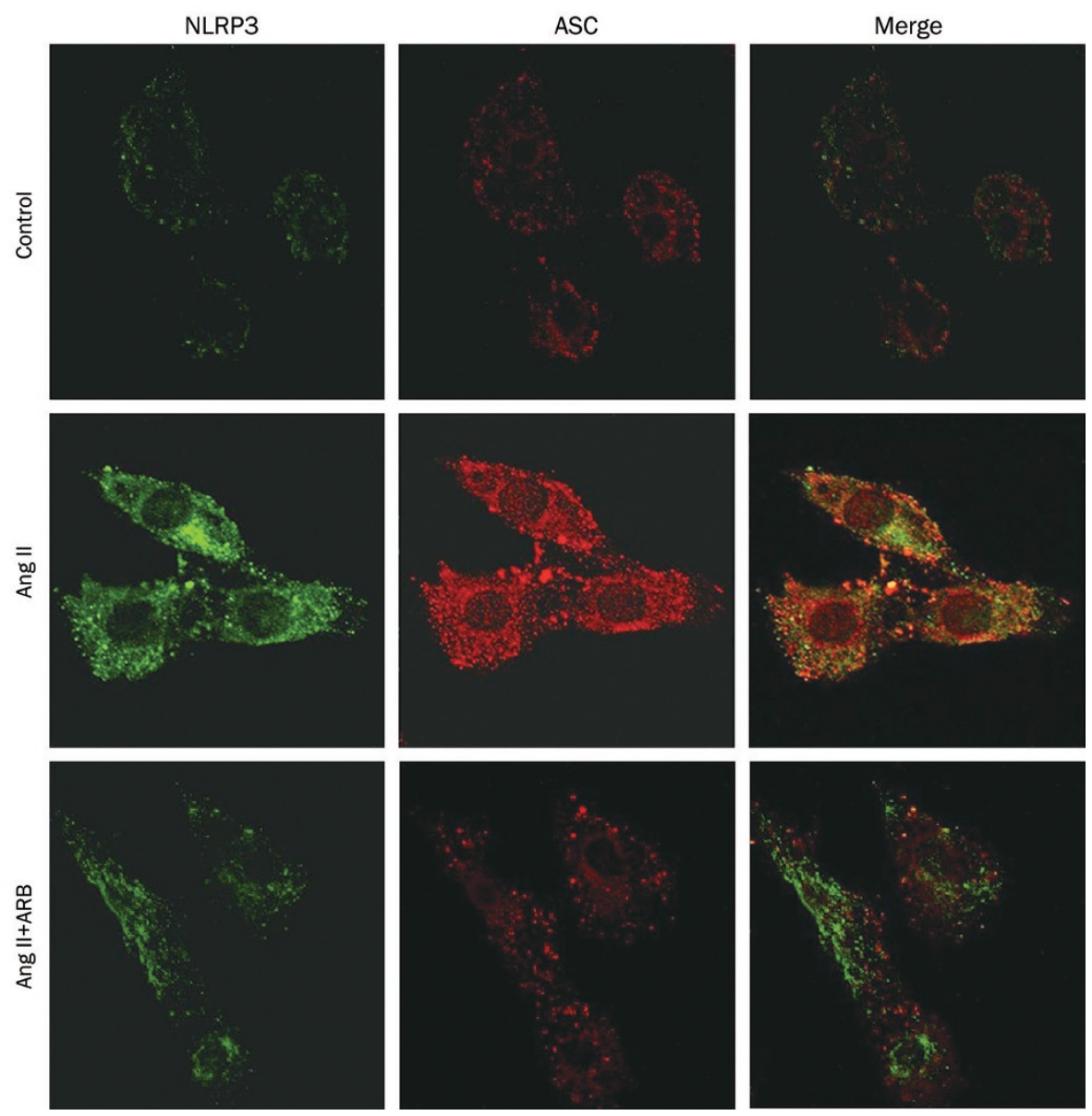

Figure 3. Telmisartan could inhibit angiotensin II-induced NLRP3 inflammasome activation. The inflammasome markers (NLRP3 and ASC) were detected by indirect immunostaining in HK-2 cells. HK-2 cells were treated without or with $100 \mathrm{nmol} / \mathrm{L}$ angiotensin II or with $100 \mathrm{nmol} / \mathrm{L}$ angiotensin II and $1 \mu \mathrm{mol} / \mathrm{L}$ telmisartan (ARB) for $12 \mathrm{~h}$ in serum-free medium.

Dahl salt-sensitive (DSS) hypertensive rats, olmesartan could significantly attenuate HS-induced increases in mRNA levels of proinflammatory cytokines and inflammatory cell accumulation ${ }^{[15]}$. Xie et al $l^{[7]}$ also showed that Ang II treatment could lead to an increasing expression of proinflammatory cytokines (IL-1 $\beta$, IL-6, IL-8, and TNF- $\alpha$ ). However, the mechanism by which Ang II induces renal inflammation is still unclear. To date, investigators have demonstrated that Ang II mediates renal inflammation through the activation of several intracellular signaling pathways, including the nuclear factor-kB (NF$\kappa B)$, mitogen-activated protein kinases (MAPK), Rho proteins and redox pathways ${ }^{[13,16,17]}$. In addition, Ang II can increase the production of mitochondrial reactive oxygen species (ROS) to induce inflammation ${ }^{[18]}$. In this study, we found that Ang II may activate the NLRP3 inflammasome to induce inflammation.

The NLRP3 inflammasome is one of the several intracellular pattern recognition receptors (PRRs) that initiate inflammation in response to hazards ${ }^{[19]}$. The inflammasome converts inactive pro-caspase- 1 to active caspase- 1 , which cleaves inactive cytokine precursors (such as pro-IL-1 $\beta$, pro-IL-18) into a secreted and active form ${ }^{[20]}$. Accumulating studies now sug- gest that the NLRP3 inflammasome in intrarenal dendritic cells or infiltrating macrophages drives renal inflammation ${ }^{[21,22]}$. In addition, in vivo studies have indicated that the NLRP3 inflammasome plays an important role in renal inflammation by infiltrating leukocytes and increasing pro-inflammatory cytokine (IL-1 $\beta$, IL-18) expression ${ }^{[10]}$. Our previous studies using BSA-overload rats have demonstrated that the expression of the NLRP3 inflammasome is increased; however, treatment with enalapril, a well-known angiotensin converting enzyme inhibitor, inhibited tubulointerstitial inflammation and reduced the expression of the NLRP3 inflammasome ${ }^{[12]}$.

In this study, we focused on the role of Ang II in the expression of NLRP3 in renal tubular cells. We found that Ang II could induce NLRP3 inflammasome activation in a dose- and time-dependent manner in renal tubular epithelial cells. Additionally, to examine whether this phenomenon was actually caused by Ang II, we used telmisartan to inhibit the action of angiotensin II. We found that telmisartan could significantly inhibit angiotensin II induced NLRP3 inflammasome activation. Because increasing evidence demonstrates that ER stress may induce inflammasome activation through a mechanism involving reactive oxygen species formation and activation of 
A

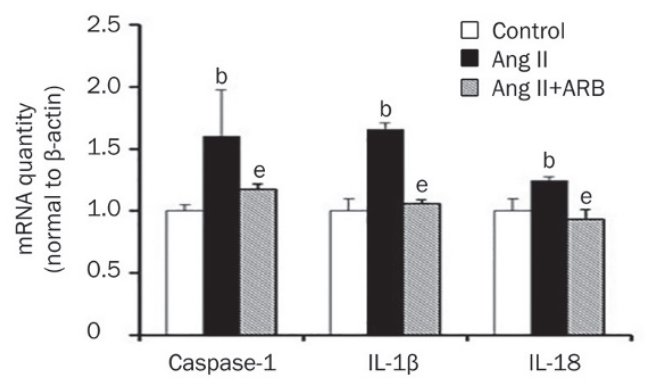

C

Caspase-1-p10

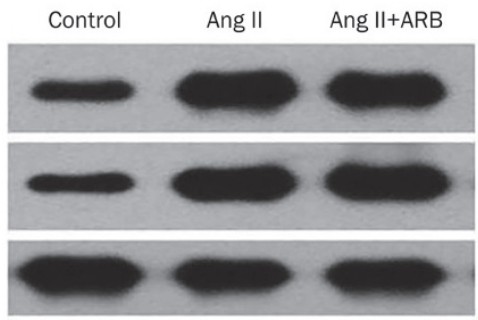

E

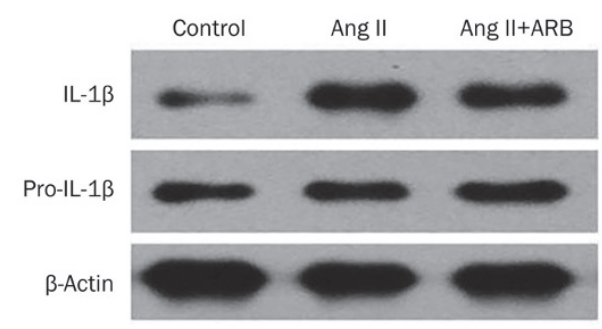

G

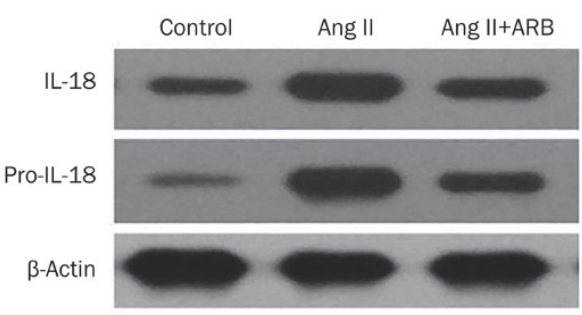

I

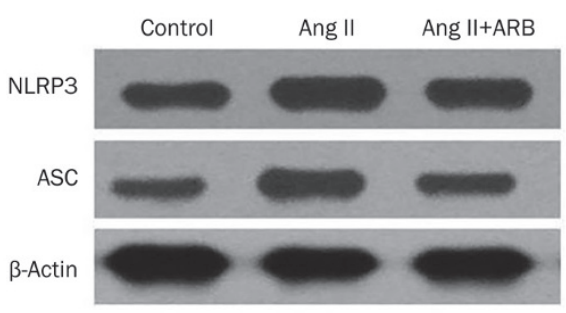

B

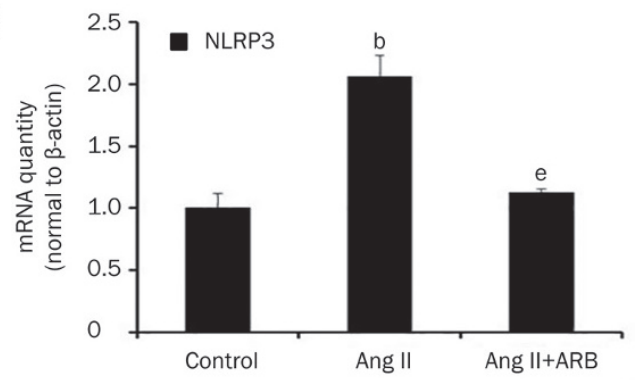

D

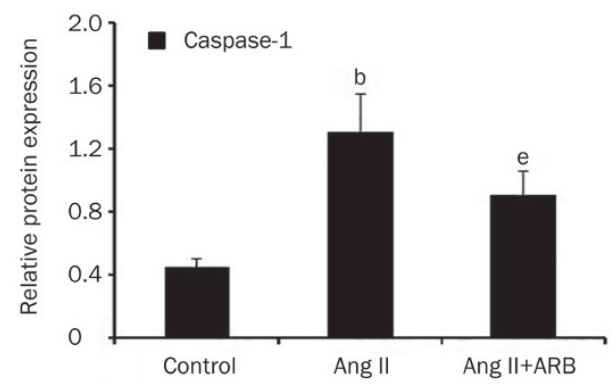

F

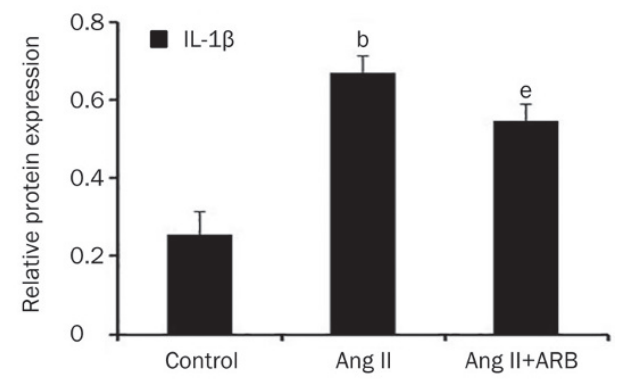

$\mathrm{H}$

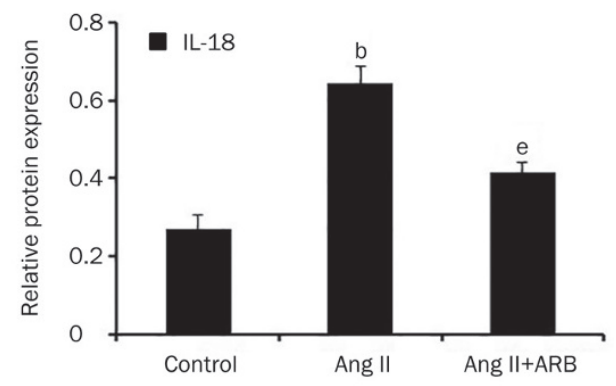

J

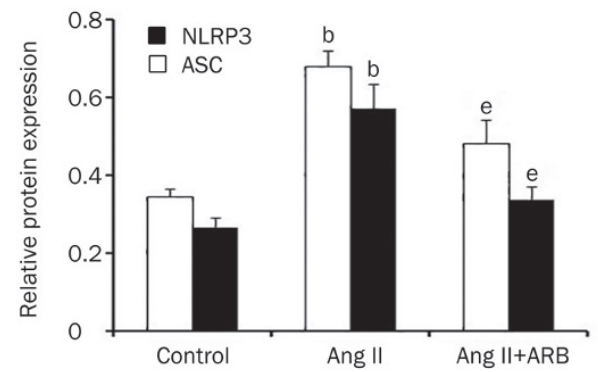

Figure 4. Telmisartan could inhibit angiotensin II-induced NLRP3 inflammasome activation. (A and B) Real-time PCR and (C-J) Western blot analysis show that the mRNA and protein expression of NLRP3, ASC, caspase-1, IL-1B, and IL-18 were reduced after pretreatment with telmisartan (1 $\mu$ mol/L). $\beta$-Actin served as an internal control gene. The results represent the mean \pm SD from three experiments. ${ }^{\mathrm{b}} P<0.05$ vs control. ${ }^{\mathrm{e}} P<0.05$ vs the Ang II group. 


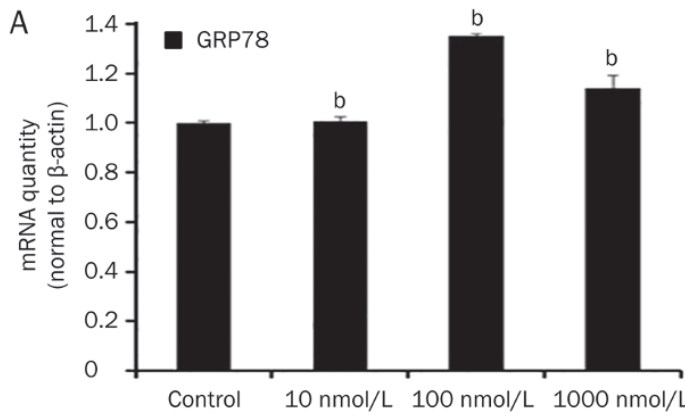

C
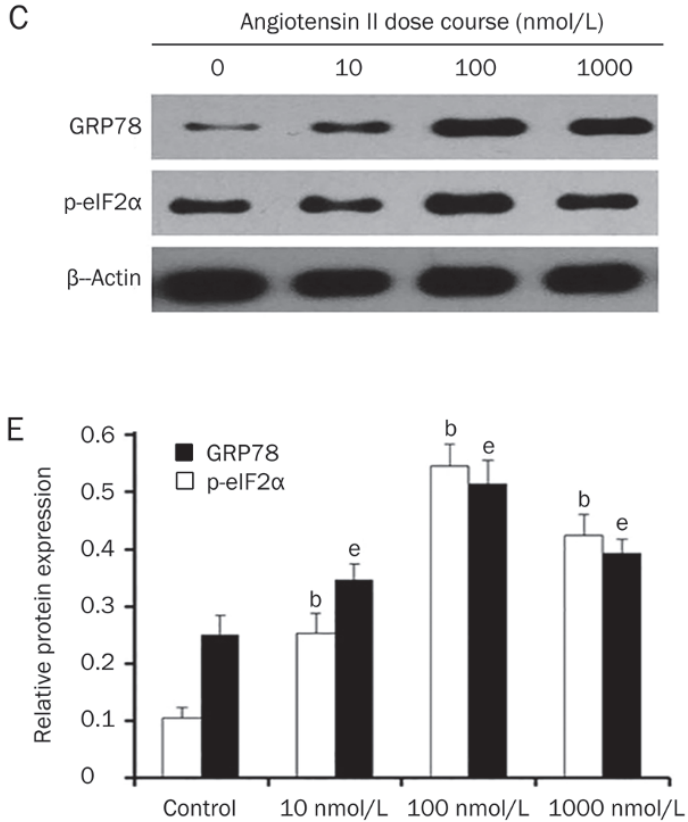

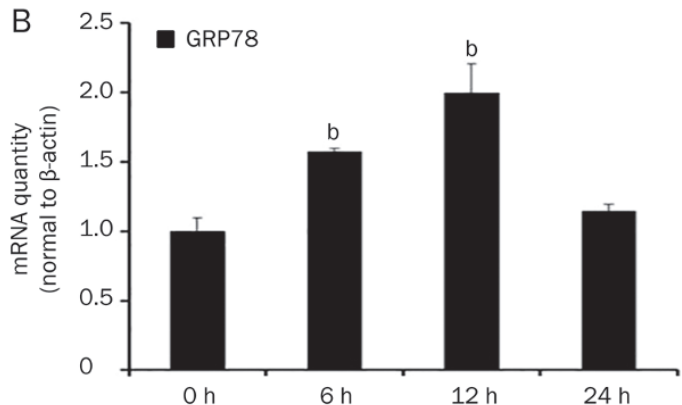

D
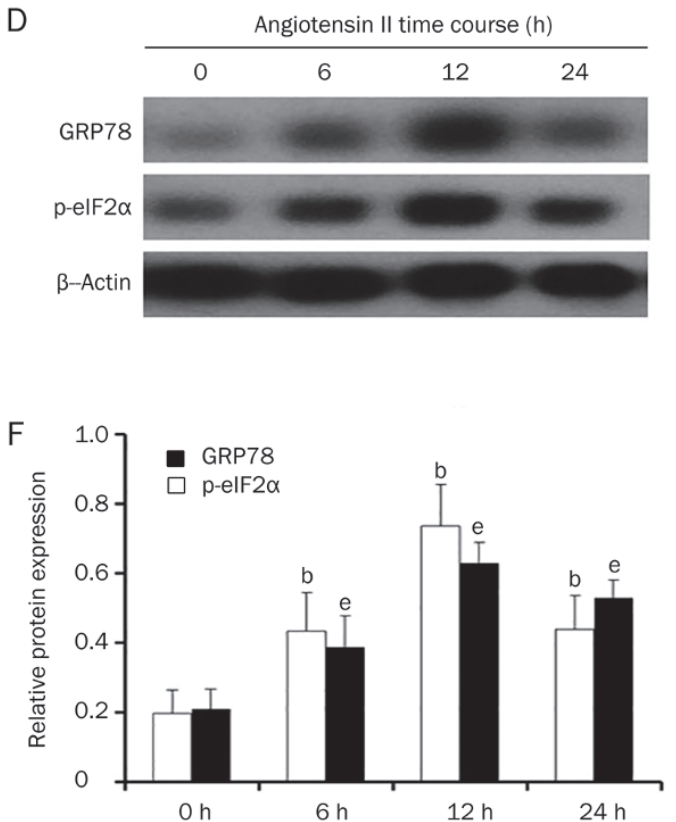

Figure 5. Angiotensin II could induce endoplasmic reticulum stress in HK-2 cells. (A) Real-time PCR and (C and E) Western blot analysis show that the mRNA and protein expression of GRP78 and p-elF2 $\alpha$ were increased after treatment with different amounts $(0,10,100$, and 1000 nmol/L) of angiotensin II for $12 \mathrm{~h}$ in serum-free medium. (B) Real-time PCR and (D and F) Western blot analysis indicate that the mRNA and protein expression of GRP78 and p-elF2 $\alpha$ were increased after treatment with $100 \mathrm{nmol} / \mathrm{L}$ angiotensin II for various time periods $(0,6,12$, or $24 \mathrm{~h})$ in serum-free medium. $\beta$-Actin served as an internal control gene. The results represent the mean \pm SD from four experiments. ${ }^{b} P<0.05$ vs control (the relative abundance of GRP78 mRNA and protein). ${ }^{\mathrm{e}} \mathrm{P}<0.05$ vs control (the relative abundance of the $\mathrm{p}$-elF2 $\alpha$ protein).

thioredoxin-interacting protein ${ }^{[8,23,24]}$, we further explored the potential mechanism of Ang II in mediating NLRP3 inflammasome activation and its link to ER stress. Interestingly, we demonstrated that Ang II could induce endoplasmic reticulum stress in HK-2 cells. It was observed that 4-phenyl butyric acid (4-PBA), a well-known ER stress inhibitor ${ }^{[25]}$, significantly reduced the expression of NLRP3, ASC, caspase-1, IL-1 $\beta$, and IL-18 induced by Ang II, suggesting that ER stress might be involved in Ang II-induced NLRP3 inflammasome activation in HK-2 cells. Previously, we demonstrated that albumin could induce the activation of intrarenal $\operatorname{RAS}^{[26]}$, and other studies have shown that albumin might induce endoplasmic reticulum stress ${ }^{[27]}$, which may play an important role in regulating inflammation. Taken together, our results may provide a new mechanism for inflammation induced by albuminuria.

In recent years, numerous studies in human and animal models have shown that inflammasomes play an important role in acute and chronic kidney disease $\mathrm{s}^{[10,20,28]}$. Our present study demonstrated that telmisartan could inhibit NLRP3 inflammasome activation, suggesting that angiotensin II receptor blockers may slow the progression of chronic kidney diseases by inhibiting inflammasome activation in addition to lowering blood pressure.

In conclusion, our findings demonstrated for the first time that Ang II could induce inflammasome activation in HK-2 cells, and ER stress may be involved in this important process. This finding may represent a newly identified mechanism by which the renal RAS system can induce renal tubulointerstitial inflammation.

\section{Acknowledgements}

This study was supported by grants from the National Natural Science Foundation of China (№ 81130010), the Major State Basic Research Development Program ("973") (№ 


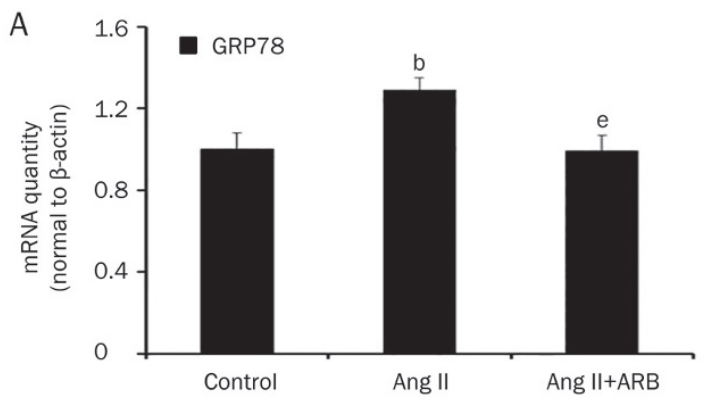

B
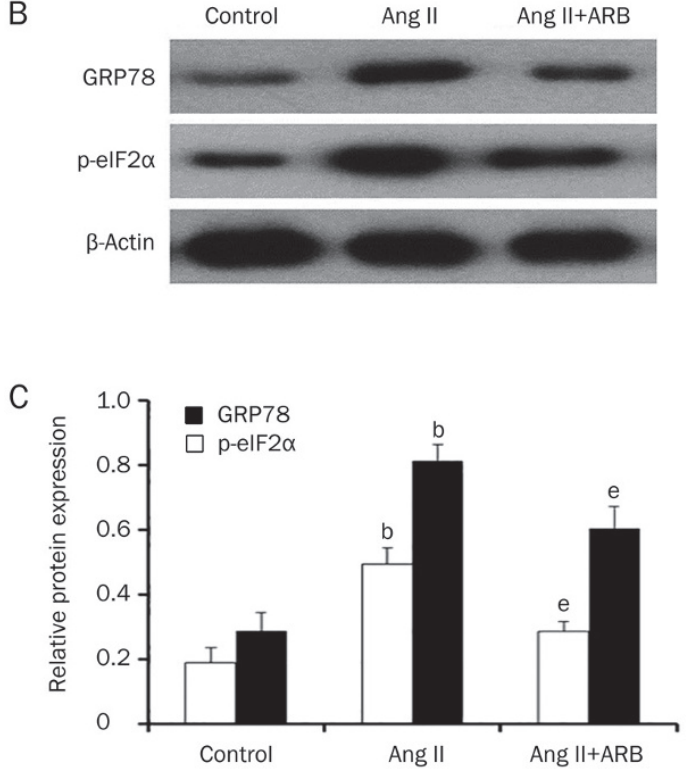

Figure 6. Telmisartan could inhibit angiotensin Il-induced endoplasmic reticulum stress. (A) Real-time PCR and (B and C) Western blot analysis show that the mRNA and protein expression of GRP78 and p-elF2 $\alpha$ were reduced after pretreatment with telmisartan $(1 \mu \mathrm{mol} / \mathrm{L})$. The results represent the mean $\pm S D$ from three experiments. ${ }^{\mathrm{b}} P<0.05$ vs control. ${ }^{\mathrm{e}} \mathrm{P}<0.05$ vs the Ang II group.

2012CB517706), and the Program for Jiangsu Clinical Research Center, China (No BL2014080).

\section{Author contribution}

Jing WANG and Bi-cheng LIU conceived the study and designed the experiments; Jing WANG and Yi WEN performed the experiments; Jing WANG, Yi Wen, Lin-li LV, Hong LIU, Ri-ning TANG, Kun-ling MA, and Bi-cheng LIU analyzed the data; Jing WANG wrote the manuscript; Bi-cheng LIU designed the study and reviewed the manuscript.

\section{References}

1 Chuang PY, Menon MC, He JC. Molecular targets for treatment of kidney fibrosis. J Mol Med 2013; 91: 549-59.

2 Silverstein DM. Inflammation in chronic kidney disease: role in the progression of renal and cardiovascular disease. Pediatr Nephrol 2009; 24: 1445-52.

3 Kobori H, Nangaku M, Navar LG, Nishiyama A. The intrarenal renin- angiotensin system: from physiology to the pathobiology of hypertension and kidney disease. Pharmacol Rev 2007; 59: 251-87.

4 Ruster C, Wolf G. Renin-angiotensin-aldosterone system and progression of renal disease. J Am Soc Nephrol 2006; 17: 2985-91.

5 Lin L, Phillips WE, Manning RD. Intrarenal angiotensin II is associated with inflammation, renal damage, and dysfunction in dahl salt-sensitive hypertension. J Am Soc Hypertens 2009; 3: 306-14.

6 Alique M, Civantos E, Sanchez Lopez E, Lavoz C, Rayego Mateos S, Rodrigues Díez $\mathrm{R}$, et al. Integrin-linked kinase plays a key role in the regulation of angiotensin II-induced renal inflammation. Clin Sci 2014; 127: 19-31.

7 Xie P, Joladarashi D, Dudeja P, Sun L, Kanwar YS. Modulation of angiotensin II-induced inflammatory cytokines by the Epac1-Rap1ANHE3 pathway: implications in renal tubular pathobiology. Am J Physiol Renal Physiol 2014; 306: F1260-74.

8 Menu P, Mayor A, Zhou R, Tardivel A, Ichijo H, Mori K, et al. ER stress activates the NLRP3 inflammasome via an UPR-independent pathway. Cell Death Dis 2012; 3: e261.

9 Bauernfeind F, Ablasser A, Bartok E, Kim S, Schmid-Burgk J, Cavlar T, et al. Inflammasomes: current understanding and open questions. Cell Mol Life Sci 2011; 68: 765-83.

10 Vilaysane A, Chun J, Seamone ME, Wang W, Chin R, Hirota S, et al. The NLRP3 inflammasome promotes renal inflammation and contributes to CKD. J Am Soc Nephrol 2010; 21: 1732-44.

11 Schroder K, Tschopp J. The Inflammasomes. Cell 2010; 140: 82132.

12 Ding LH, Liu D, Xu M, Liu H, Wu M, Tang RN, et al. Enalapril inhibits tubulointerstitial inflammation and NLRP3 inflammasome expression in BSA-overload nephropathy of rats. Acta Pharmacol Sin 2014; 35: 1293-301.

13 Ruiz-Ortega M, Ruperez M, Esteban V, Rodriguez-Vita J, Sanchez-Lopez E, Carvajal G, et al. Angiotensin II: a key factor in the inflammatory and fibrotic response in kidney diseases. Nephrol Dial Transpl 2005; 21: $16-20$

14 Ruiz-Ortega M, Bustos C, Hernandez-Presa MA, Lorenzo O, Plaza JJ, Egido J. Angiotensin II participates in mononuclear cell recruitment in experimental immune complex nephritis through nuclear factor-kappa $B$ activation and monocyte chemoattractant protein-1 synthesis. J Immunol 1998; 161: 430-9.

15 Rafiq K, Nishiyama A, Konishi Y, Morikawa T, Kitabayashi C, Kohno $\mathrm{M}$, et al. Regression of glomerular and tubulointerstitial injuries by dietary salt reduction with combination therapy of angiotensin II receptor blocker and calcium channel blocker in dahl salt-sensitive rats. PLoS One 2014; 9: e107853.

16 Ruiz-Ortega M, Lorenzo O, Suzuki Y, Rupérez M, Egido J. Proinflammatory actions of angiotensins. Curr Opin Nephrol Hypertens 2001; 10: 321-9.

17 Liu G, Li Y, Huang XR, Wei L, Chen H, Shi Y, et al. Disruption of Smad7 promotes ANG II-mediated renal inflammation and fibrosis via Sp1TGF- $\beta /$ Smad3-NFKB-dependent mechanisms in mice. PLoS One 2013; 8: e53573.

18 Dikalov SI, Nazarewicz RR. Angiotensin II-induced production of mitochondrial reactive oxygen species: potential mechanisms and relevance for cardiovascular disease. Antioxid Redox Signal 2013; 19: 1085-94

19 Lorenz G, Darisipudi MN, Anders HJ. Canonical and non-canonical effects of the NLRP3 inflammasome in kidney inflammation and fibrosis. Nephrol Dial Transpl 2014; 29: 41-8.

20 Anders HJ, Muruve DA. The inflammasomes in kidney disease. J Am Soc Nephrol 2011; 22: 1007-18.

21 Darisipudi MN, Thomasova D, Mulay SR, Brech D, Noessner E, Liapis 
A

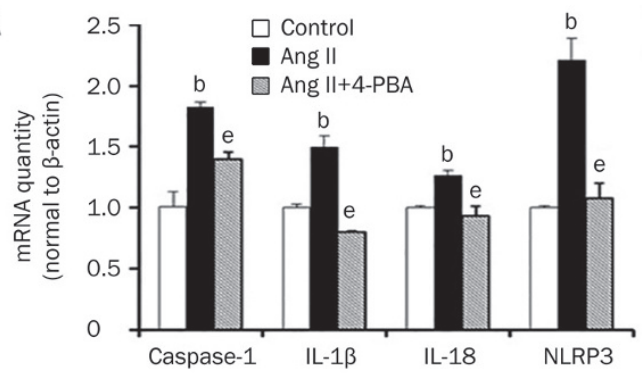

C

E

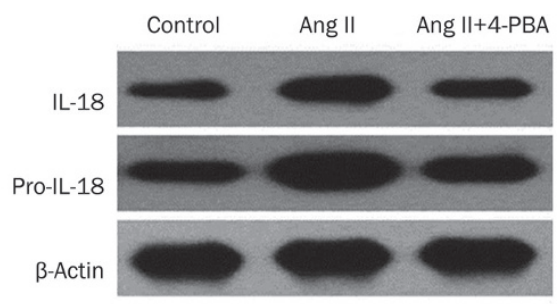

G

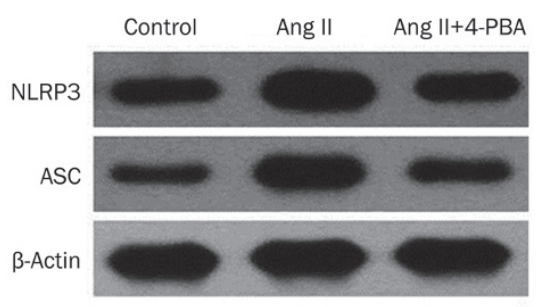

I

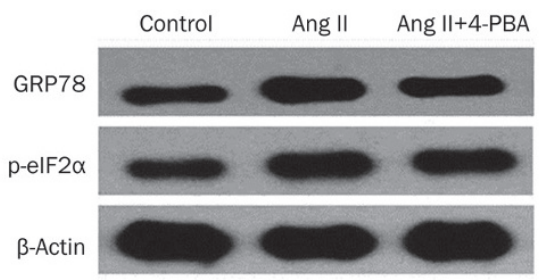

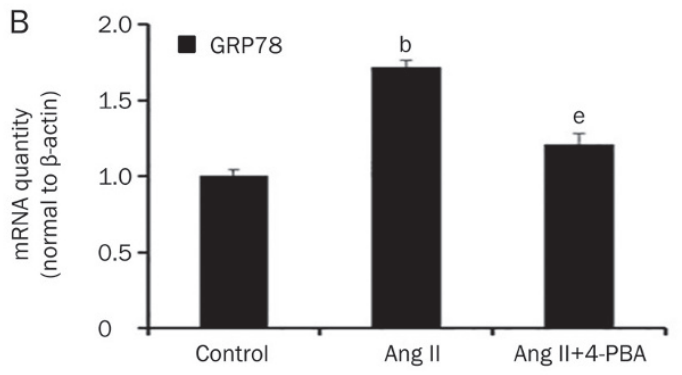

D

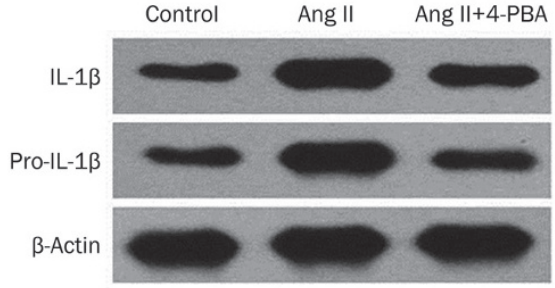

$\mathrm{F}$

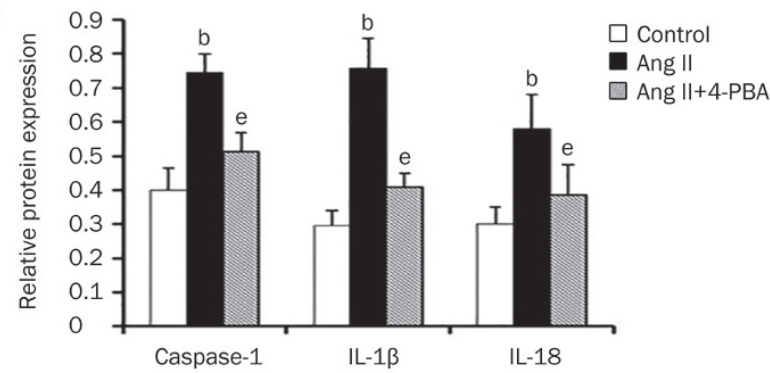

$\mathrm{H}$

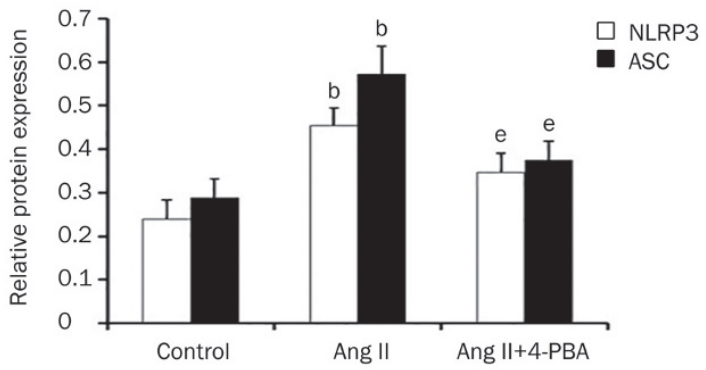

J

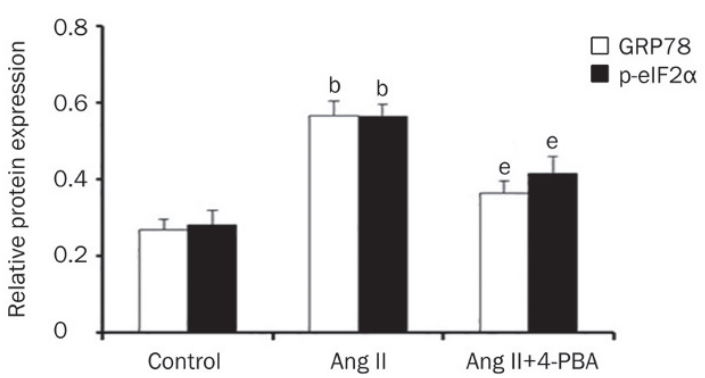

Figure 7. 4-PBA could inhibit angiotensin II-induced NLRP3 inflammasome activation. (A and B) Real-time PCR and (C-J) Western blot analysis show that the mRNA and protein expression of NLRP3, ASC, caspase-1, IL-1B, IL-18, GRP78, and p-elF2 $\alpha$ were reduced after pretreatment with 4-PBA (5 $\mathrm{mmol} / \mathrm{L}$ ). The results represent the mean \pm SD from three experiments. ${ }^{\mathrm{b}} P<0.05$ vs control. ${ }^{\mathrm{e}} P<0.05$ vs the Ang II group. 
$\mathrm{H}$, et al. Uromodulin triggers IL-1-dependent innate immunity via the NLRP3 inflammasome. J Am Soc Nephrol 2012; 23: 1783-9.

22 Mulay SR, Kulkarni OP, Rupanagudi KV, Migliorini A, Darisipudi MN, Vilaysane A, et al. Calcium oxalate crystals induce renal inflammation by NLRP3-mediated IL-1 $\beta$ secretion. J Clin Invest 2013; 123: 236-46.

23 Kim S, Joe Y, Jeong SO, Zheng M, Back SH, Park SW, et al. Endoplasmic reticulum stress is sufficient for the induction of IL-1beta production via activation of the NF-kappaB and inflammasome pathways. Innate Immun 2014; 20: 799-815.

24 Oslowski CM, Hara T, O'Sullivan-Murphy B, Kanekura K, Lu S, Hara M, et al. Thioredoxin-interacting protein mediates ER stress-induced beta cell death through initiation of the inflammasome. Cell Metab 2012; 16: $265-73$.
25 Koyama M, Furuhashi M, Ishimura S, Mita T, Fuseya T, Okazaki Y, et al. Reduction of endoplasmic reticulum stress by 4-phenylbutyric acid prevents the development of hypoxia-induced pulmonary arterial hypertension. Am J Physiol Heart Circ Physiol 2014; 306: H1314-23.

26 Liu B, Gao J, Li Q, Xu L. Albumin caused the increasing production of angiotensin II due to the dysregulation of ACE/ACE2 expression in HK2 cells. Clin Chim Acta 2009; 403: 23-30.

27 Fang L, Xie D, Wu X, Cao H, Su W, Yang J. Involvement of endoplasmic reticulum stress in albuminuria induced inflammasome activation in renal proximal tubular cells. PLoS One 2013; 8: e72344.

28 Shigeoka AA, Mueller JL, Kambo A, Mathison JC, King AJ, Hall WF, et al. An inflammasome-independent role for epithelial-expressed NIrp3 in renal ischemia-reperfusion injury. J Immunol 2010; 185: 6277-85. 